\title{
Pedagogia: identidade e formação O trabalho pedagógico nos Processos Educativos Não-Escolares
}

\author{
Ricardo Antunes de Sá*
}

\begin{abstract}
RESUMO
O texto procura caracterizar a dimensão pedagógica dos processos educativos não-escolares, a partir da compreeensão teórico-metodológica do trabalho como princípio educativo. Evidencia o papel epistemológico da Pedagogia enquanto ciência aplicada da e para a prática educativa, que estuda as diversas manifestações do fenômeno educativo, inclusive a caracterização da dimensão pedagógica dos espaços educativos não-escolares. Palavras-chave: Educação, Pedagogia, Processos Educativos Não-Escolares.
\end{abstract}

\begin{abstract}
This study aims at characterizing pedagogical dimension of educational processes that are not formal, by examining work as an educational process from a theoretical perspective. It focuses on Pedagogy's episthemological role as applied science and its contribution to the educational practice studied, within a wide range of educational phenomena, the pedagogic dimension in educational settings which are not schooling patterned.

Key-words: Education, Pedagogy; Education Processes Not Formal.
\end{abstract}

* Mestre em Educação pela UFPR. Coordenador do Curso de Pedagogia da UFPR na Gestão 97/99 e Professor do Curso de Pedagogia. Texto apresentado na 22. ${ }^{a}$ Reunião da ANPEd/Debate - Pedagogia: identidade e formação, em Caxambú - MG/setembro de 1999. ricardo@prograd.ufpr.br 


\section{Introdução}

Os estudos e debates sobre a formação e atuação do Pedagogo, ao longo desses trinta anos, se caracterizaram pela construção da identidade deste profissional e da ciência que lhe dá suporte epistemológico, a Pedagogia, pela superação ou não das habilitações, bem como na busca necessária de articulação da Pedagogia com as demais licenciaturas.

A presente reflexão quer contribuir para a fundamentação e discussão que se instala a respeito do trabalho pedagógico nos processos educativos não-escolares manifestos no setor produtivo, nos movimentos sociais e nas entidades da sociedade civil no atual contexto brasileiro contemporâneo. $\mathrm{O}$ papel do pedagogo na articulação do conhecimento e das ações no âmbito da sociedade civil organizada. A organização da práxis pedagógica na educação não escolar, na perspectiva do trabalho como princípio educativo.

\section{Contextualizando as condições histórico-sociais}

Hoje, final dos anos noventa, praticamente na virada para o terceiro milênio, testemunha-se a complexidade da sociedade urbanizada industrial ou pós-industrial. $\mathrm{O}$ advento da ciência e da técnica aplicadas cada vez mais ao desenvolvimento dos processos de produção material com a inserção da base microeletrônica flexibilizando e alterando substancialmente a organização, o planejamento na produção das mercadorias, acelerando a extração da maisvalia relativa, a informatização dos dados, seu armazenamento e possibilidades de acesso em tempo real, a robotização da produção industrial se constituem em novas formas de produzir e reproduzir a existência humana, novas possibilidades de alienação e/ou de superação.

O processo de globalização frenético da economia permite

[...] a reprodução ampliada do capital, compreendendo a concentração e a centralização, o desenvolvimento das forças produtivas e das relações de produção em escala mundial [...] A sociedade global já é uma realidade, não só em termos econômicos, mas também políticos, sociais e culturais [...] Ocorre que o mesmo processo de globalização da cultura, caminhando junto [...] ainda que de forma 
desigual, globaliza também grupos e classes sociais, movimentos sociais e partidos políticos, ideologias e utopias. (IANNI, 1993, p. 47-50).

Globaliza-se a questão do desemprego, a qualificação/desqualificação do trabalhador, a desregulamentação do trabalho (contrato temporário e/ou parcial de trabalho) (MATTOSO, 1995), (ANTUNES, 1996), (IANNI, 1996), (FERRETI, 1994), da perda dos direitos constitucionais dos trabalhadores e cria-se novos termos, novos slogans como empregabilidade, torna-se o indivíduo empregável num mar de desatinados, de desesperados de despossuídos, uma crescente exclusão de grandes contingentes de seres humanos dos bens gerados pela sociedade multimídia.

A hegemonização das novas formas de comunicação e informação redefinem os mecanismos de disseminação da informação, tornando os acontecimentos conhecidos em tempo real, o tempo da disseminação de uma concepção ideológica, que encontra eco no senso comum das classes dominantes e dos dominados.

A intimidação do Estado frente às contradições sociais e seu papel de condutor das políticas neoliberais que privilegiam a eqüidade em detrimento do direito à universalidade...

Tudo isso têm construído nas últimas décadas, sobretudo, uma trama histórico-societária que faz emergir novos atores e novos espaços privados de hegemonia no âmbito da sociedade civil que, contraditoriamente, reproduzem/produzem processos educativos de formação/deformação, de alienação/desalienação da cidadania.

Desta maneira, sem aqui desconsiderar o papel e a função social preponderante que a escola teve, ao longo desses duzentos anos, e tem no processo de emancipação da grande maioria da população dos Estados nacionais, outros espaços educativos se manifestam na sociedade capitalista mundializada, é preciso que a Universidade, que a Pedagogia, ciência que estuda o fenômeno educativo escolar e não-escolar, passe a estudar e formar intelectuais, pedagogos para atuarem com competência epistêmico-política e técnica nestes novos cenários criados nas e pelas relações sociais.

Portanto, pretende-se, nestas considerações, traçar um percurso necessário para fundamentar teórica e metodologicamente a compreensão da dimensão pedagógica implícita no espaço educativo não-escolar e as possibilidades de atuação do Pedagogo.

Para identificar a possibilidade de atuação do Pedagogo, enquanto educador e intelectual no âmbito da sociedade civil, é necessário partir de um referencial teórico-metodológico que caracterize, do ponto de vista 
epistemológico e político, a dimensão pedagógica do trabalho que se manifesta em cada espaço de atividade não-escolar.

\section{O Trabalho Como Princípio Educativo como fundamento para a compreensão da dimensão pedagógica dos processos educativos não-escolares}

O trabalho é o princípio fundamental que caracteriza o homem como ser humano, que é síntese de múltiplas determinações: econômicas, sociais, históricas, psicológicas, culturais, educacionais e ideológicas. Constrói-se nas relações que estabelece na prática social, mediatizando, pelo trabalho, sua relação com a natureza, consigo mesmo e com os outros homens.

Assim, pois, a atividade do trabalho é entendida como princípio fundamental para se entender o homem como ser humanizado. Não se pode ser plenamente humano se não se puder trabalhar, exercer atividade teórico/prática na sociedade.

Tomando o trabalho como princípio educativo, entender-se-á que este, possui, então, no seu processo dinâmico, dois pólos que se articulam contraditoriamente: a teoria e a prática, a concepção e a execução, o saber e o fazer.

Com efeito, o princípio do trabalho é apreendido como referencial teórico porque , dentro de uma pedagogia sociohistórica de formação humana, explicita a compreensão da produção e manutenção da existência histórica do homem concreto.

Desta forma, o ser humano, no embate com a natureza para assegurar sua sobrevivência, trabalhando, "vai construindo o mundo histórico, vai construindo o mundo da cultura, o mundo humano." (SAVIANI, 1991, p. 97)

É a partir daí que a educação aparece como forma de responder às necessidades da sociedade de perpetuar sua produção não-material, sua cultura, seus costumes, seus ritos, seus mitos.

Se o princípio do trabalho explicita a produção teórico/prática da existência humana, é através dela que o homem produz sua existência material, $o$ conhecimento, a cultura, as artes. A forma com que cada sociedade organiza sua produção material e espiritual, cria um dado princípio organizador e orientador, um princípio educativo que assumirá configurações distintas ao longo da história. 
Na sociedade ocidental moderna, o trabalho assume, no conjunto das relações sociais e de produção capitalistas, uma ruptura entre a relação teoria e prática. Como afirma Kuenzer:

Se tal ruptura não é possível ao nível do trabalho no seu acontecendo, o mesmo não ocorre ao nível das relações sociais capitalistas, que operam a ruptura entre teoria e prática, decisão e ação, trabalho intelectual e trabalho manual. ( KUENZER, 1988, p. 18-19)

O trabalho, no nível das relações sociais no modo de produção capitalista, construir-se-á pela ruptura da unidade dialética entre teoria e prática. $\mathrm{O}$ princípio educativo, que se configura aí, parte da divisão social e técnica do trabalho e este referencial, ou melhor, este princípio organizador acabará moldando as formações sociais e culturais da sociedade burguesa.

Se a base produtiva que produz e reproduz a existência do homem no capitalismo fragmenta concepção e execução, teoria e prática, trabalho intelectual e trabalho manual, a formação dos homens nesta sociedade criará indivíduos "intelectuais" e indivíduos "manuais".

A formação dos intelectuais é, pois, reflexo das condições materiais de produção, porquanto condiciona o surgimento do cidadão-intelectual e do cidadão-manual. $\mathrm{O}$ ingresso no mercado de trabalho se efetivará pelas condições de classe social, ficando as ocupações hierarquizadas entre aquelas consideradas teóricas, intelectuais e aquelas denominadas de manuais, técnicas ou de execução.

Levando em consideração que o trabalho no nível das relações sociais capitalistas assume uma determinada concepção fragmentada e alienada, a intenção aqui é registrar o entendimento do princípio educativo do trabalho no seu conceito geral e situá-lo no contexto do atual modo de produção, contudo, o recorte que se deseja demarcar aqui, sem descontextualizar, é a ênfase na dimensão pedagógica do trabalho educativo nos processos de formação humana não-escolares.

Portanto, partindo-se da concepção teórico/prática de que é no e pelo trabalho que o homem vai se construindo e construindo suas relações sociais mais amplas, é, também, por sua ação teórico/prática material ou não-material que vai gerando socialmente o conhecimento, a ciência, a educação e as explicações para os fenômenos naturais e humanos.

Se o trabalho é um princípio que educa, que transforma e que produz conhecimento, sob a atuação intencional do sujeito histórico, aquele então, apresenta uma Dimensão Pedagógica. 
Qual é a Dimensão Pedagógica implícita no trabalho educativo nãoescolar, por exemplo, desenvolvido nas instituições que trabalham com a terceira idade? Qual é a dimensão pedagógica implícita nas atividades das ONG'S que defendem os direitos das mulheres, dos negros, dos homossexuais? Qual é a dimensão pedagógica que está presente nos trabalhos das comunidades, nas associações de moradores, nos movimentos dos sem terra, dos sem teto, dos favelados, dos encortiçados etc.? Há uma dimensão pedagógica nas instituições públicas e/ou privadas que defendem e trabalham pela prevenção à Síndrome de Imunodeficiência Adquirida, flagelo planetário, com consequiências, quem sabe até, para a própria sobrevivência das próximas gerações? Qual são os elementos definidores que possibilitem a mídia eletrônica um trabalho pedagógico de inculcação e de manipulação de consciências, interferindo no comportamento, na cultura, sobretudo, da grande maioria da população domiciliada, pela hegemonia da ideologia dominante, no senso comum, que a própria mídia reforça?

Portanto, a questão é como caracterizar esta dimensão nos espaços de trabalho (não-material) educativos não-escolares?

Como se organizam? Com e por quais finalidades existem? Qual sua especificidade? Qual é o conhecimento produzido, gerado, nesta práxis que define sua natureza sociohistórica e qual a contribuição que proporcionam no sentido de transformarem ou não as circunstâncias e as consciências?

Que situações estão sendo engendradas nesse espaço que apontam para uma forma de "educação" contribuindo no processo de humanização e emancipação do homem? Qual a concepção pedagógico-política que sustenta as atividades educativas desses novos cenários? Qual seria a utopia manifesta e as suas possibilidades concretas de materialização a partir do espaço do trabalho não-escolar?

É preciso, pois, captar, compreender a especificidade, a história, o discurso, a cultura, as mediações que constroem o trabalho educativo não-escolar e as relações que desenvolve com a sociedade civil.

Buscar caracterizar a Dimensão Pedagógica é buscar possibilidades de educação para a cidadania, para a melhoria de qualidade de vida e da comunidade. É vislumbrar as possibilidades e os limites das instituições sociais na construção de um processo de hegemonização do discurso solidário e transformador.

Apreender a Dimensão Pedagógica do trabalho educativo não-escolar no âmbito das relações contraditórias da sociedade contemporânea é entender as possibilidades históricas de transformação social através do trabalho de elevação cultural e moral dos sujeitos históricos, partindo do pensamento gramsciano, tomar o núcleo do bom senso existente no senso comum e, à luz da 
natureza de cada espaço de trabalho educativo não-escolar, trabalhar para que as pessoas de uma determinada comunidade atendida ou participante daquela instituição ampliem suas possibilidades de atuarem como cidadãos engajados na construção de uma nova hegemonia social.

\section{A identidade da Pedagogia: condição científico-política necessária na demarcação de sua especificidade e a formação do Pedagogo}

Para atuar nos espaços de trabalho educativo não-escolares, que pertencem ao âmbito da sociedade civil (nas instituições públicas e privadas, organizações produtivas, nos movimentos sociais organizados etc.), enfim, atividades nas quais se reproduzem em nível de superestrutura, a lógica contraditória da emancipação/exploração, da libertação/servilismo, da transformação/conservação, constitui-se condição científico-política a demarcação da identidade epistemológica da Pedagogia e as possibilidades de atuação do Pedagogo.

Em vários trabalhos científicos recentes, autores como: FREITAS (1985 e 1986), PIMENTA (1999), LIBÂNEO (1999) e outros têm pesquisado e sistematizado conhecimento a respeito da demarcação da identidade epistemológica da Pedagogia e suas conseqüências para a construção de uma Teoria Pedagógica, de um Discurso Pedagógico consistente e conseqüente, bem como para própria identidade do Pedagogo.

Está claro que a Pedagogia é uma ciência aplicada da e para a Prática Educativa, compreendendo aqui as escolares e as não-escolares. Reveste-se de um discurso próprio, constrói suas próprias categorias de análise do fenômeno educativo a partir das contribuições de outras ciências que se debruçam sobre os processos de formação humana, porém não se confunde com os saberes científicos elegidos por aquelas.

E por que a existência de uma identidade epistemológica?

Ora, as práticas educativas escolares e não-escolares se caracterizam por serem atividades desenvolvidas pelos homens em situações histórico-sociais definidas, imersos num determinado modo de produzir a existência material e espiritual. Esta práxis educativa, este trabalho, tem uma intencionalidade ético-política, se organiza de uma dada maneira, está implícita ou explicita uma determinada metodologia com o objetivo de atingir fins definidos, há sujeitos destinatários ou partícipes envolvidos nesta práxis. 
QUINTANA E CABANAS (1983), citado por PIMENTA (1999), considera que a Pedagogia não se dilui nas ciências da Educação, afirma-a como ciência prática e normativa da educação, preocupada com a ação de educar, com o ato educativo e com a intervenção nesse ato, para o qual se dirige a um só tempo com a intenção de conhecê-lo e de transformá-lo, munida de uma intencionalidade, de um projeto.

Para que seja possível construir, sistematizar e formar futuros intelectuais, dirigentes e técnicos, os licenciados, que dominem os fundamentos epistêmicos da ciência da Educação para compreender e interferir, do ponto de vista de sua especificidade, nos novos cenários educativos que se criam no conjunto das novas relações societárias contemporâneas, sua formação não poderá se dar fora do locus universitário. Por quê ?

Só a Universidade poderá garantir, através das suas atividades de pesquisa, ensino e extensão, as devidas condições acadêmico-científicas para uma formação de qualidade. A interlocução com as diversas e diversificadas áreas do conhecimento é fundamental para uma ciência aplicada como a Pedagogia. A História, Filosofia, Sociologia, Psicologia e Antropologia têm fundamentado a produção de uma Teoria Pedagógica, porém outros aportes teóricos se mostram prementes para entendermos as determinações complexas que permeiam as relações superestruturais de uma "comunidade" global e que interferem e determinam a constituição desses novos espaços não-formais de manifestação humana.

A Economia, a Psicanálise, a Comunicação, a Lingüística, a Informática, o Direito e outras ciências necessárias no auxílio à construção do Discurso Pedagógico, são demandadas pelo conteúdo específico do trabalho pedagógico não-escolar, que é o critério e referência na produção do conhecimento, dos saberes e das práticas.

Em documento de julho deste ano a ANFOPE reafirmou que as Universidades e suas Faculdades/Centros de Educação constituem o locus privilegiado da formação dos profissionais da educação e considera a docência como base da identidade profissional de todos os profissionais da educação que atuarem nas diversas áreas da educação formal e não-formal (ANFOPE, 1999, $\mathrm{s} / \mathrm{n})$.

Por que a docência como base da identidade do Pedagogo ?

Tentando argumentar sob o recorte da temática específica deste escrito, dir-se-ia que a atuação do sujeito histórico e do intelectual no processo de trabalho educativo não-escolar se caracteriza na postura e na atitude de um "professor". Não estamos falando do professor clássico da organização escolar, mas sua atuação demanda intencionalidade, um tipo ou forma de organizar sua atividade, preocupação com encaminhamentos técnico-metodológicos 
para repassar determinado conhecimento ou informação que instrumentalize seu ou seus interlocutores para além do senso comum, na perspectiva de transformação.

Portanto, entendemos que há uma ação docente intrínseca na prática educativa escolar e na não-escolar, é uma postura intencionalizada que possui suas nuances em função das especificidades das naturezas dos locus de formação humana, porém a atividade docente é basilar.

KUENZER (1998), no documento intitulado "A formação dos profissionais da Educação: proposta de Diretrizes Curriculares Nacionais ", argumenta, citando documento da UnB/Faculdade de Educação, que:

O eixo de sua formação (dos profissionais da Educação, do Pedagogo) é o trabalho pedagógico escolar e não-escolar, que tem na docência, compreendida como ato educativo intencional, o seu fundamento.

É a ação docente, portanto, o elemento catalizador de todo o processo de formação do profissional de educação, a partir da qual as demais ciências se aglutinarão para dar suporte à investigação e à intervenção sobre os processos de formação humana. É a partir dela (docência), de sua natureza e de suas funções, que se materializa o trabalho pedagógico, com suas múltiplas facetas, espaços e atores.

[...] Esta forma de conceber, que toma a ação docente como fundamento do trabalho pedagógico, determina que os processos de formação dos profissionais da educação tenham organicidade a partir de uma base comum - os processos educativos em sua dimensão de totalidade - sobre a qual dar-se-ão os recortes específicos, em termos de aprofundamento.

A Pedagogia, enquanto ciência que estuda o fenômeno educativo em sua totalidade, complexidade e historicidade, tem na academia as condições científico-culturais para produzir a teoria Pedagógica e não fora dela.

Todavia, é preciso urgentemente repensarmos a concepção, a organização e as estruturas das Faculdades/Centros de Educação.

A licenciatura de Pedagogia, no quadro dos profissionais da educação, deve perseguir sua identidade epistêmico-política através de uma base comum nacional, anunciada em 1983 pela Comissão Nacional de Reformulação dos Cursos de Formação do Educador (CONARCFE) como "[...] sólida concepção básica de formação do educador alicerçada em um corpo de conhecimento fundamental. [...] consubstanciada num tríplice aspecto: na dimensão profissional, política e epistemológica, ancorada numa concepção sociohistórica de educador". (CONARCFE, 1983, p. 5)

Ter na docência sua identidade profissional não significa reduzir a ação pedagógica à docência, mas incorporá-la como um determinante estrutural na compreensão e intervenção da e na práxis educativa, efetivando, com isto, 
uma concepção unitária de formação do Pedagogo para atuar na educação escolar e não-escolar.

\section{REFERÊNCIAS}

ANFOPE - ASSOCIAÇÃO NACIONAL PARA A FORMAÇÃO DOS PROFISSIONAIS EM EDUCAÇÃO - Campinas, 1999. Mimeog.

ANTUNES, R. Adeus ao trabalho? 2. ed. São Paulo: Cortez/Editora da UNICAMP, 1995.

CONARCFE - COMISSÃO NACIONAL DE REFORMULAÇÃO DOS CURSOS DE FORMAÇÃO DE EDUCADORES - I Encontro Nacional - Belo Horizonte, 1983. p. 5, mimeog.

FREITAS, L. C. A especificidade da Educação e a formação do Pedagogo. Goiânia: Cortez, 1986.

. Notas sobre a especificidade do Pedagogo e sua responsabilidade no estudo da teoria e prática pedagógicas. Educação de Sociedade, São Paulo, n. 22, p. 12-19, 1985.

FERRETTI, C. J. (Org.). Tecnologias, trabalho e Educação. Petrópolis: Vozes, 1994.

IANNI, O. A sociedade global. 2. ed. Rio de Janeiro: Civilização Brasileira, 1993.

KUENZER, A. et al. Educação e trabalho. Salvador: Fator, 1988.

et al. A formação dos profissionais da Educação: proposta de Diretrizes Curriculares Nacionais. Curitiba: Setor de Educação, 1998. Mimeog.

LIBÂNEO, J. C. Que destino os educadores darão à Pedagogia ? In: PIMENTA, S. G. et al. (Org.). Pedagogia, ciência da Educação? São Paulo: Cortez, 1996.

. Pedagogia, pedagogos, para quê? São Paulo: Cortez, 1998.

MATTOSO, J. E. A desordem do trabalho. São Paulo: Scritta, 1995.

PIMENTA, S. G. O pedagogo na escola pública. São Paulo: Loyola, 1988.

. (Org.) Pedagogia, ciência da Educação? São Paulo: Cortez, 1996.

. (Org.) Didática e formação de professores: percursos e perspectivas no Brasil e em Portugal. São Paulo: Cortez, 1997.

SAVIANI, D. Pedagogia histórico-crítica: primeiras aproximações. São Paulo: Cortez, 1991. 